2 Taylor-Robinson D, Smyth RL, Diggle P, et al. The effect of social deprivation on clinical outcomes and the use of treatments in the UK cystic fibrosis population: a longitudinal study. Lancet Respir Med 2013; 1: 121-128.

3 Beker LT, Russek-Cohen E, Fink RJ. Stature as a prognostic factor in cystic fibrosis survival. J Am Diet Assoc 2001; 101: 438-442.

4 Fogarty AW, Britton J, Clayton A, et al. Are measures of body habitus associated with mortality in cystic fibrosis? Chest 2012; 142: 712-717.

5 Fogarty AW, Lewis SA, McKeever TM, et al. The association of two different measures of body habitus with lung function: a population-based study. Respir Med 2011; 105: 1896-1901.

6 Diderichsen F, Evans T, Whitehead M. The social origins of disparities in health. Challenging inequities in health. New York, Oxford University Press, 2001.

7 Taylor-Robinson DC, Smyth R, Diggle PJ, et al. A longitudinal study of the impact of social deprivation and disease severity on employment status in the UK cystic fibrosis population. PLoS One 2013; 8: e73322.

\title{
Electronic nicotine delivery systems
}

\author{
To the Editor:
}

While reading the editorial on electronic nicotine delivery systems by BLASI and WARD [1], we noticed an inaccuracy in the section on The post-2016 regimen (p. 586). It is wrongly stated that "there will be a maximum nicotine volume for e-cigarettes of $10 \mathrm{~mL}$ for refillable cartridges". The volume of $10 \mathrm{~mL}$ was stated by the European Union in its 2014/40/EU Directive to be applicable to "refill containers" for the e-liquids that are used to refill the (maximally) $2 \mathrm{~mL}$-containing refillable cartridges of an e-cigarette [2]. In the EU Directive 2014/40/EU, it is stated in article 20.3a that "nicotine-containing liquid is only placed on the market in dedicated refill containers not exceeding a volume of $10 \mathrm{ml}$, in disposable electronic cigarettes or in single use cartridges and that the cartridges or tanks do not exceed a volume of $2 \mathrm{ml}$ " and in article $20.3 \mathrm{~b}$ that "the nicotine-containing liquid does not contain nicotine in excess of $20 \mathrm{mg} / \mathrm{ml}$."

0 $@$ ERSpublications

A correction is needed on electronic nicotine delivery systems http://ow.ly/EWkzj

Kristiaan Nackaerts ${ }^{1}$ and Luk Joossens ${ }^{2}$

${ }^{1}$ Dept of Respiratory Diseases, KU Leuven - University of Leuven, University Hospitals, Leuven, Belgium. ${ }^{2}$ Foundation against Cancer, Brussels, Belgium.

Correspondence: Kristiaan Nackaerts, University Hospital Gasthuisberg - Respiratory Oncology Herestraat 49 Leuven B3000 Belgium. E-mail: kristiaan.nackaerts@uzleuven.be

Received: Nov 052014 | Accepted: Nov 062014

Conflict of interest: None declared.

\section{References}

1 Blasi F, Ward B. Electronic nicotine delivery systems (ENDS): the beginning of the end or the end of the beginning? Eur Respir J 2014; 44: 585-588.

2 Directive 2014/40/EU of the European Parliament and of the Council of 3 April 2014 on the approximation of the laws, regulations and administrative provisions of the Member States concerning the manufacture, presentation and sale of tobacco and related products and repealing Directive 2001/37/EC. Off J Eur Union 2014; L127: 1-38.

From the authors:

We thank K. Nackaerts and L. Joossens for correctly pointing out an error in our editorial "Electronic nicotine delivery systems (ENDS): the beginning of the end or the end of the beginning?" [1]. Where the Editorial states that "there will be a maximum nicotine volume for e-cigarettes $(2 \mathrm{~mL}$ for single use and $10 \mathrm{~mL}$ for refillable cartridges), and a maximum nicotine concentration for refillable cartridges, tanks and containers of nicotine liquids ( $20 \mathrm{mg} \cdot \mathrm{mL}^{-1}$ )", it should read "according to Article 203 (a) and 203 (b) of Directive 2014/40/EU [2], 'Member States shall ensure that: (a) nicotine-containing liquid is only placed on the market in dedicated refill containers not exceeding a volume of $10 \mathrm{ml}$, in disposable electronic cigarettes or in single use cartridges and that the cartridges or tanks do not exceed a volume of $2 \mathrm{ml}$; 
(b) the nicotine-containing liquid does not contain nicotine in excess of $20 \mathrm{mg} / \mathrm{ml}$ '." This error has also been addressed as an Author Correction in this issue of the European Respiratory Journal.

@ERSpublications

A correction on electronic nicotine delivery systems http://ow.ly/EWkzj

Francesco Blasi ${ }^{1}$ and Brian Ward ${ }^{2}$

${ }^{1}$ Dept of Pathophysiology and Transplantation, University of Milan, IRCCS Fondazione Cà Granda Milano, Milan, Italy.

${ }^{2}$ European Affairs Dept, European Respiratory Society, Brussels, Belgium.

Correspondence: Francesco Blasi, Dept of Pathophysiology and Transplantation, University of Milan, IRCCS Fondazione Cà Granda Milano, Via Francesco Sforza 35, 20122 Milan, Italy. E-mail: francesco.blasi@unimi.it

Received: Nov 212014 | Accepted: Nov 212014

Conflict of interest: Brian Ward is an employee of the European Respiratory Society.

References

1 Blasi F, Ward B. Electronic nicotine delivery systems (ENDS): the beginning of the end or the end of the beginning? Eur Respir J 2014; 44: 585-588.

2 Directive 2014/40/EU of the European Parliament and of the Council of 3 April 2014 on the approximation of the laws, regulations and administrative provisions of the Member States concerning the manufacture, presentation and sale of tobacco and related products and repealing Directive 2001/37/EC. Off J Eur Union 2014; L127: 1-38.

\section{Glucocorticoids induce the production of the chemoattractant CCL20 in airway epithelium}

To the Editor:

We read with interest the report by ZiJLSTRA et al. [1] in which the effects of glucocorticoids possibly contributed to airway neutrophilia in asthma. This study nicely adds to the research demonstrating that corticosteroids not only inhibit the production of several inflammatory chemokines and cytokines, but also corticosteroids increase levels of certain regulatory proteins; these neutrophil-active proteins are potentially involved in inflammation or, indeed, in host defence. Hence, the data reported by ZiJLSTRA et al. [1] may deserve attention beyond the focus given by the authors.

Neutrophils are present in sputum of normal subjects. They are also increased in many respiratory conditions. Unsurprisingly, striking variability of sputum neutrophil counts has been demonstrated in corticosteroid-treated asthma [2] and was also recorded by ZijLSTRA et al. [1]. The notion that corticosteroids cause neutrophilia by inhibiting apoptosis of these cells is flourishing in the literature. It is so established that there is no longer any need to present supporting evidence [3]. ZIJLSTRA et al. [1] do not discuss this aspect but their choice of reference regarding neutrophilic asthma is focussed on popular roles of apoptosis.

In vitro data have, for the last two decades, suggested the possibility that corticosteroids may reduce neutrophil apoptosis. Yet, there are no known data that compellingly support a role of this pharmacological treatment in patients; quite the opposite: in a careful biopsy study, GIZYCKI et al. [4] could not find any effect of corticosteroid treatment on neutrophil apoptosis compared with placebo treatment in chronic obstructive pulmonary disease. Furthermore, UDDIN et al. [5] excluded a role of corticosteroid treatment as a factor in pro-survival activity for airway neutrophils in severe asthma. Lack of support for apoptosis-related effects actually lends weight to the findings of ZiJLSTRA et al. [1], suggesting that a chemoattractant such as CCL20 could be involved in corticosteroid-induced airway neutrophilia.

On this note, it is of interest that severe asthma is associated with upregulation of CXCL5, possibly caused in part by corticosteroid treatment [6]. Furthermore, FuKaKusA et al. [7] demonstrated that systemic 